\title{
Development of the earthquake information system for local regions using minimum seismic network and neural network technology
}

Yoshiya Oda ${ }^{1,2}$, Katsushige Ishii ${ }^{1}$, Takahiro Ishizaki ${ }^{1}$, Takahiro Iwatete ${ }^{1}$ and Mao-Hong $\mathrm{Yu}^{2}$ (1: Tokyo Metropolitan University, 2: Xi'an Jiaotong University)

\section{Introduction}

In order to reduce the earthquake disaster, it is very important to know the strong ground motion after a big earthquake as soon as possible. In Japan high-density seismograph networks were installed after the Hanshin-Awaji earthquake. It seems to be enough density to know the strong ground motion of anywhere in Japan.

The Hanshin-Awaji earthquake showed us the importance of the self-help and mutual help by citizen. The high-density seismic networks in Japan are enough on governmental viewpoint. However, there are many cities and towns that have few seismographs. It is not enough seismograph density for civilian self-disaster prevention. What is the solution? The best way is to install more and more seismographs and to monitor earthquakes. But it would request huge cost to keep the system and much time to bring all the data. The second best is to simulate strong ground motions on calculator beforehand. However, three-dimensional high accuracy and high-resolution subsurface structure, source parameter and long time for calculation would be requested. It is too difficult to acquire these data.

In this article, therefore, we will try to estimate high-resolution strong ground motion distribution using two seismograph data and neural network algorithm. Zushi is chosen as the applied site. Zushi is the city in Kanagawa prefecture located at the northeastern part of the Miura peninsula.

\section{Method}

In order to estimate peak ground acceleration (PGA) distribution, artificial neural network is applied. The neural network has one input layer, two hidden layers and one 
output layer (Figure 1). There are four units in input layer. Two PGA data observed at seismic stations, H/V peak frequency and soil zoning data are input to units of input layer. $\mathrm{H} / \mathrm{V}$ peak frequency data are picked up by spectral analysis of microtremor measurements. $\mathrm{H} / \mathrm{V}$ peak frequency is well known as the data that has correlation with amplification ratio.

This method has three periods, the observation period, the training period and the application period.

For the observation period, temporary seismic observation by as many stations as possible is carried out for a few years. Microtremor measurements are also carried out in this period. In addition, the soil zoning data is needed. These data are used for training in the training period.

For the training period, the neural network learns the relationship between PGA data, $\mathrm{H} / \mathrm{V}$ peak frequency data and the soil zoning data. After the training, the neural network is ready to estimate the PGA distribution using PGA data at only two seismic stations.

\section{Data}

\section{Earthquake data}

There are 6 seismic stations, K1, K2, K3, K4, K5 and K6 in Zushi (Figure 2). 5 stations (K1-K5) are on the surface and one station (K6) is approximately $30 \mathrm{~m}$ depth under $\mathrm{K} 1$. $\mathrm{K} 6$ is the newest station and has few data therefore $\mathrm{K} 1-\mathrm{K} 5$ data are used in this study. $\mathrm{K} 1$ and $\mathrm{K} 3$ are chosen as the stations that would be used for input data in application period. 104 earthquakes were detected from 1994 to 2003. 35 earthquakes that recorded at both $\mathrm{K} 1$ and $\mathrm{K} 3$ are selected and PGA at each station of each earthquake was calculated for the training.

\section{Microtremor data}

Microtremor measurements were carried out in Zushi. The number of observation points was 60 (Figure 2). H/V peak frequency was picked up after spectral analysis. $\mathrm{H} / \mathrm{V}$ peak frequency was typically $2 \mathrm{~Hz}-3 \mathrm{~Hz}$.

\section{Soil zoning data}


There is the soil zoning map of Zushi city that was reported in the regional disaster prevention plan of Zushi city (1994). There are 5 classes that were classified by thickness of alluvium and results of microtremor measurements. The number of data is 913 and data spacing is $100 \mathrm{~m}$ (Figure 3).

\section{Blind test}

In order to confirm accuracy of this method, the blind test was done. For the blind test, one of the observed data was excluded in training period. After the training the neural network estimates the PGA of excluded station.

Figure 4 shows the relation between estimated PGA and observed PGA. Estimated PGA is not exactly correct but reasonable. This result shows that the neural network is able to estimate the PGA of the point where the seismic station was not installed.

\section{Application}

The neural network learned earthquake data, microtremor data and soil zoning data. Figure 5 shows the process of training. After 200,000 times iteration, the error became within about 0.1 . The error is normalized differences between estimated PGA and observed PGA. In this case output value was normalized and 1.0 means $50.0 \mathrm{~cm} / \mathrm{s} / \mathrm{s}$ therefore the 0.1 error means the $5 \mathrm{~cm} / \mathrm{s} / \mathrm{s}$ error.

After the training, the PGA distributions of two cases were estimated. One is the mid chiba earthquake (M4.7) and the other is the northern chiba earthquake (M4.6). Figure 6 and Figure 7 show the estimated PGA distribution map of each case. The differences between the estimated PGA and the observed PGA are not so large. The neural network estimates PGA distribution with good accuracy.

\section{Conclusions}

To estimate the high-resolution PGA distribution map from minimum seismograph 
network immediately after a big earthquake, the new method using neural network is developed.

As the results of the blind test the neural network is able to estimate the PGA of the point where the seismic station was not installed.

This method is applied for Zushi to estimate the PGA distribution map. As the results, this method estimates the PGA distribution map of unknown earthquakes with good accuracy. 


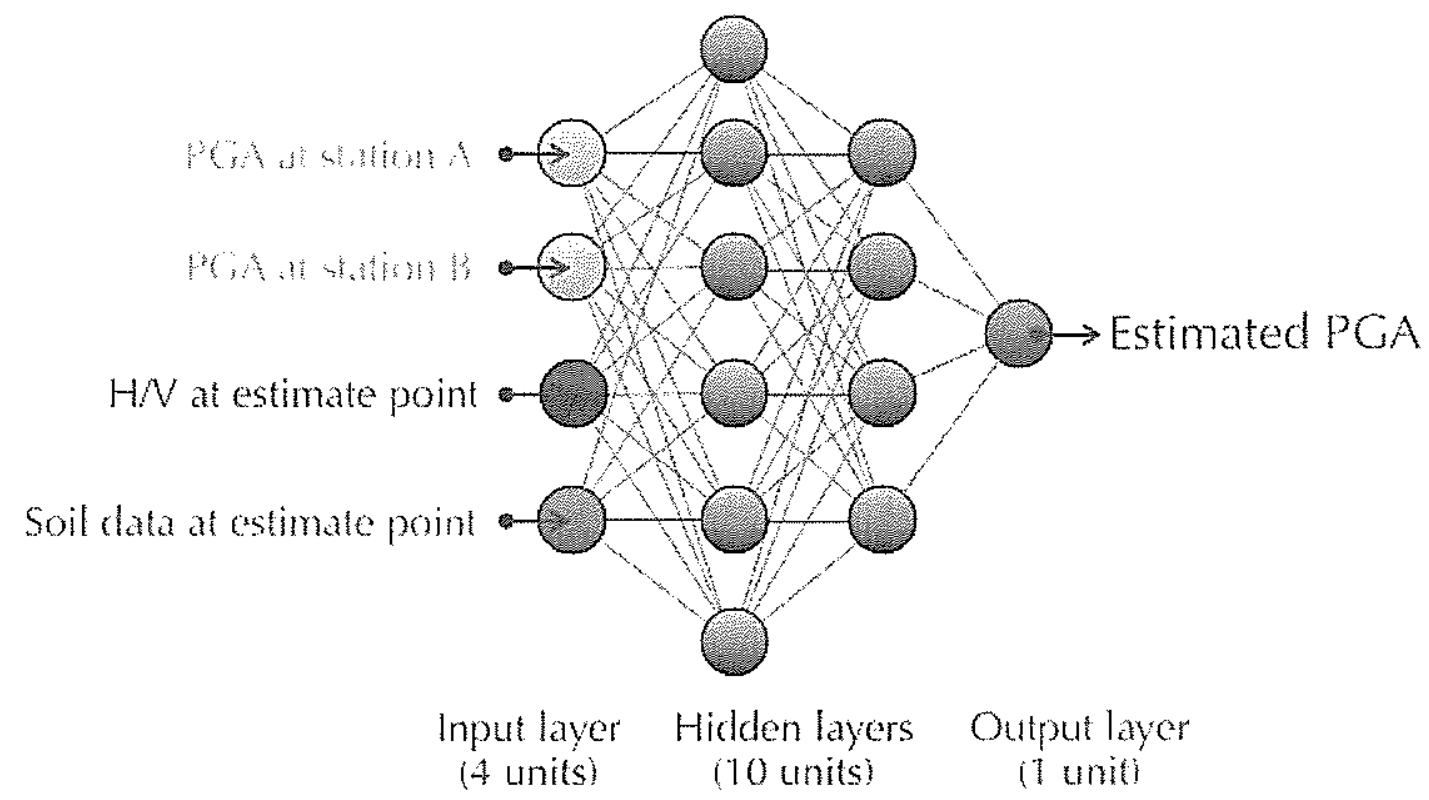

Figure 1 Structure of the neural network in this article.

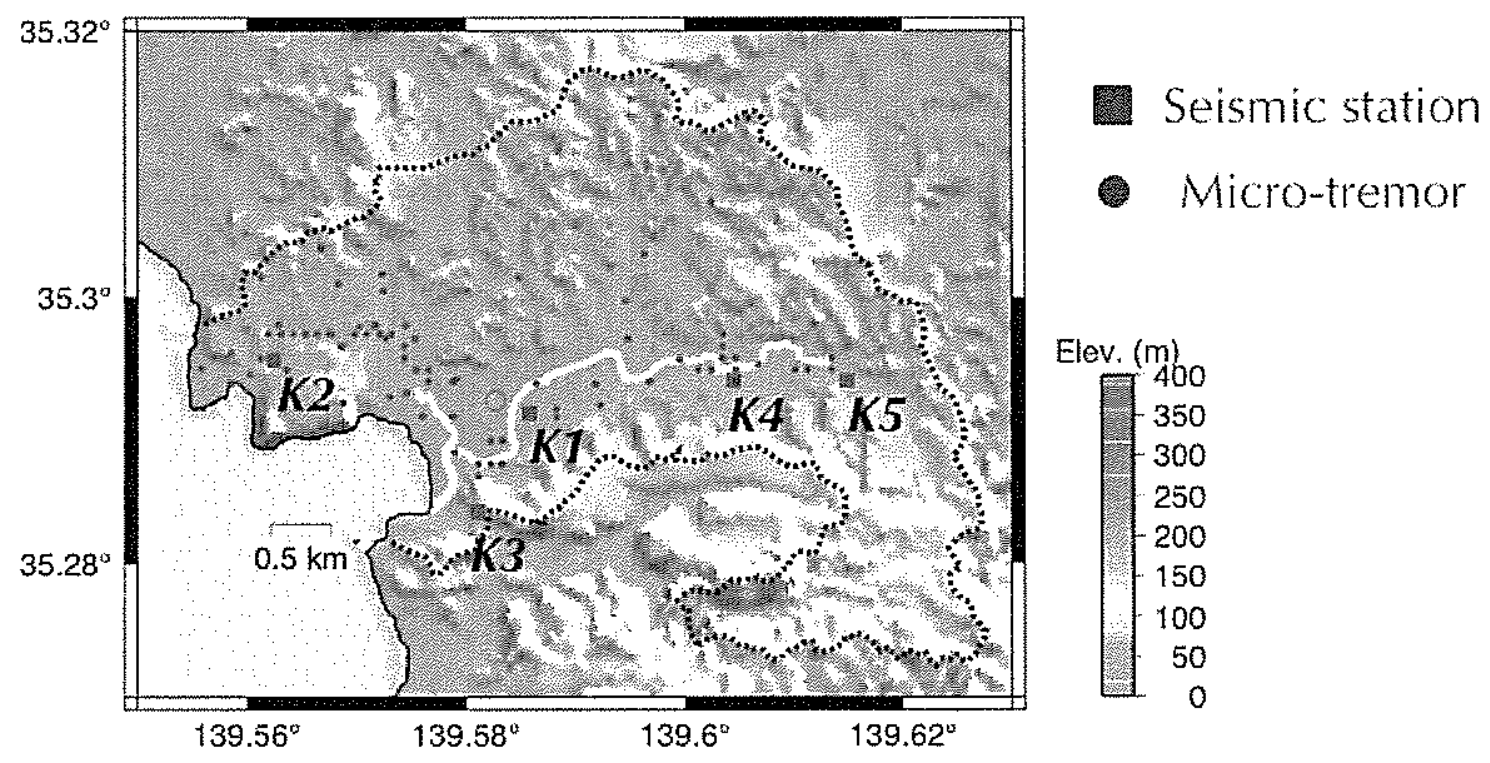

Figure 2 Location of the seismic stations and points of microtremor measurements in Zushi. 


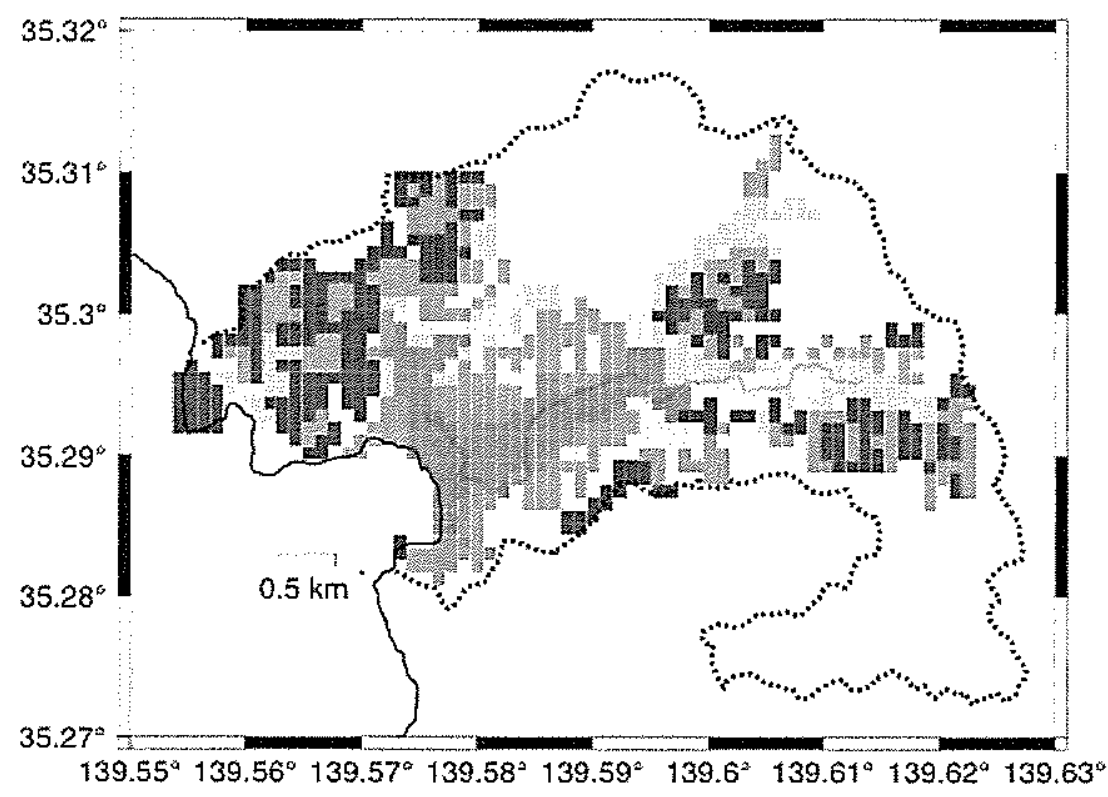

Figure 3 Soil zoning map of Zushi.
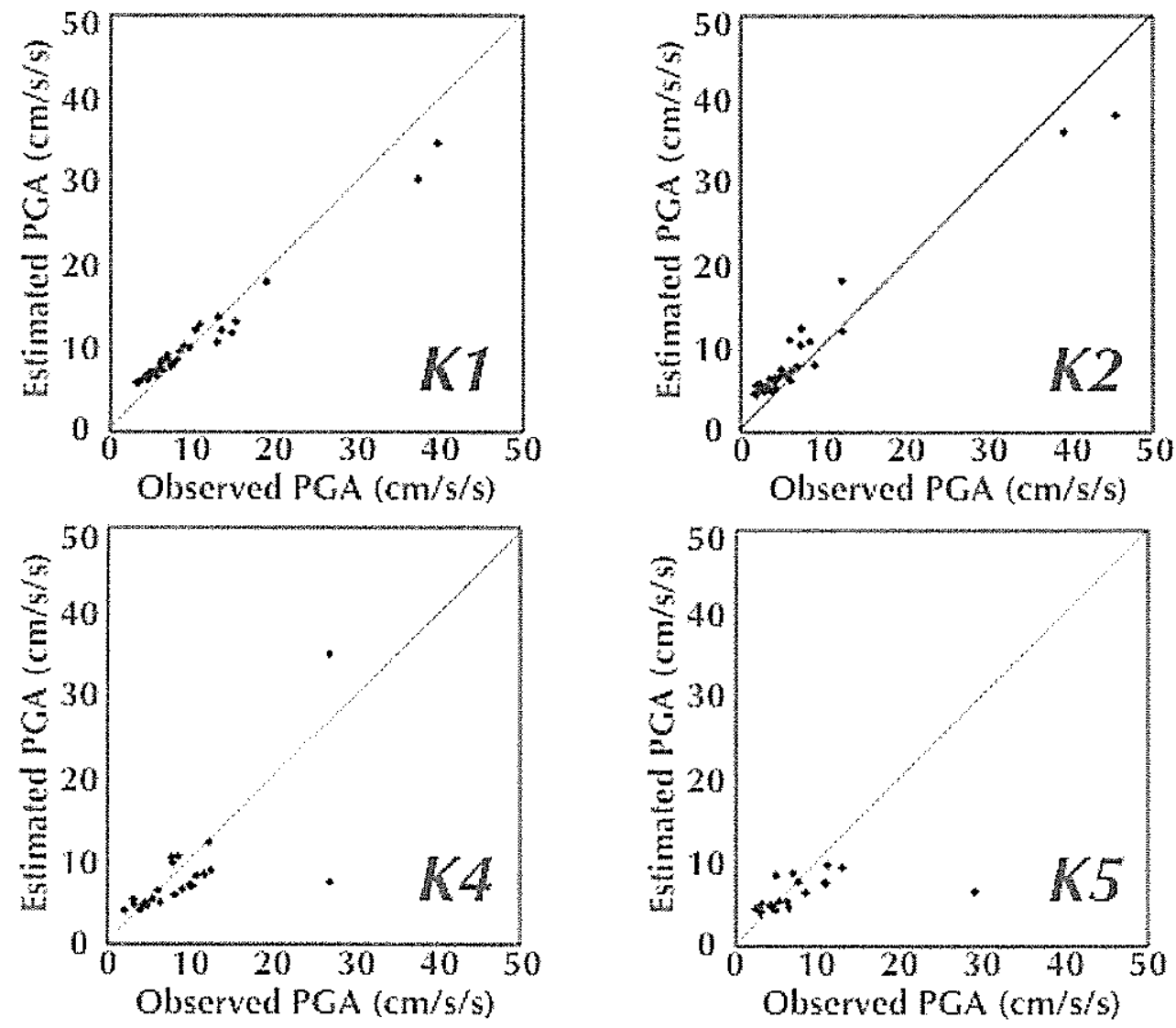

Figure 4 Results of blind test. 


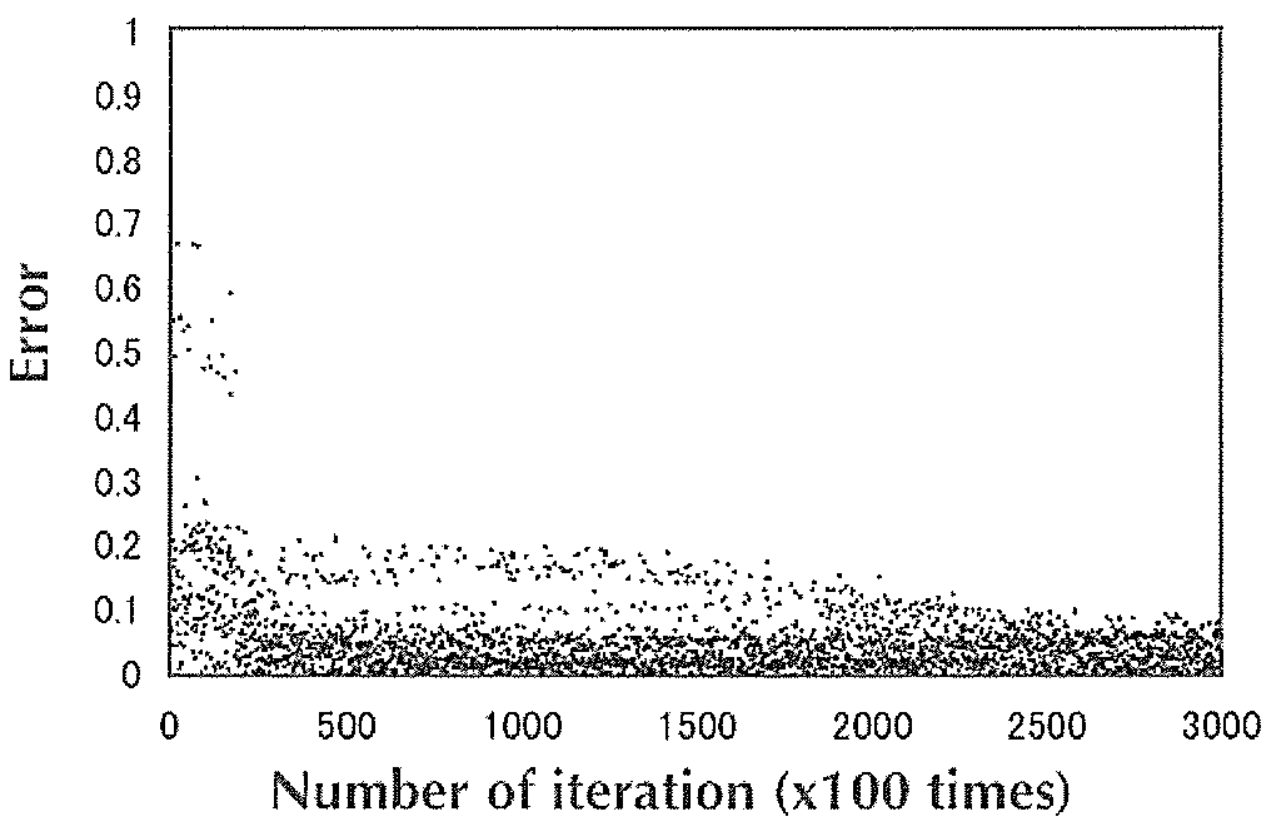

Figure 5 Training process

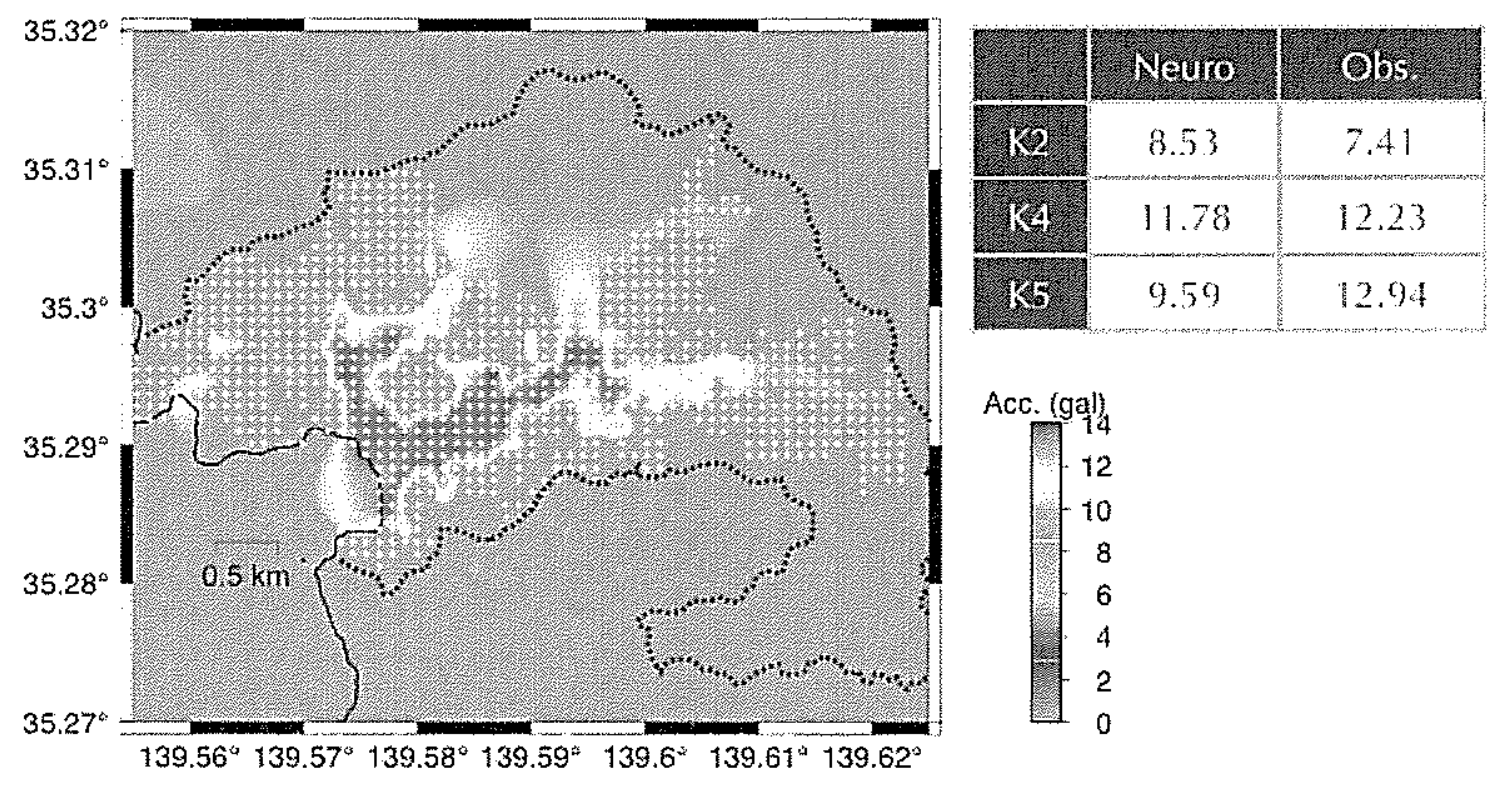

Figure 6 Estimated PGA distribution map for case 1 (Mid Chiba M4.7) 


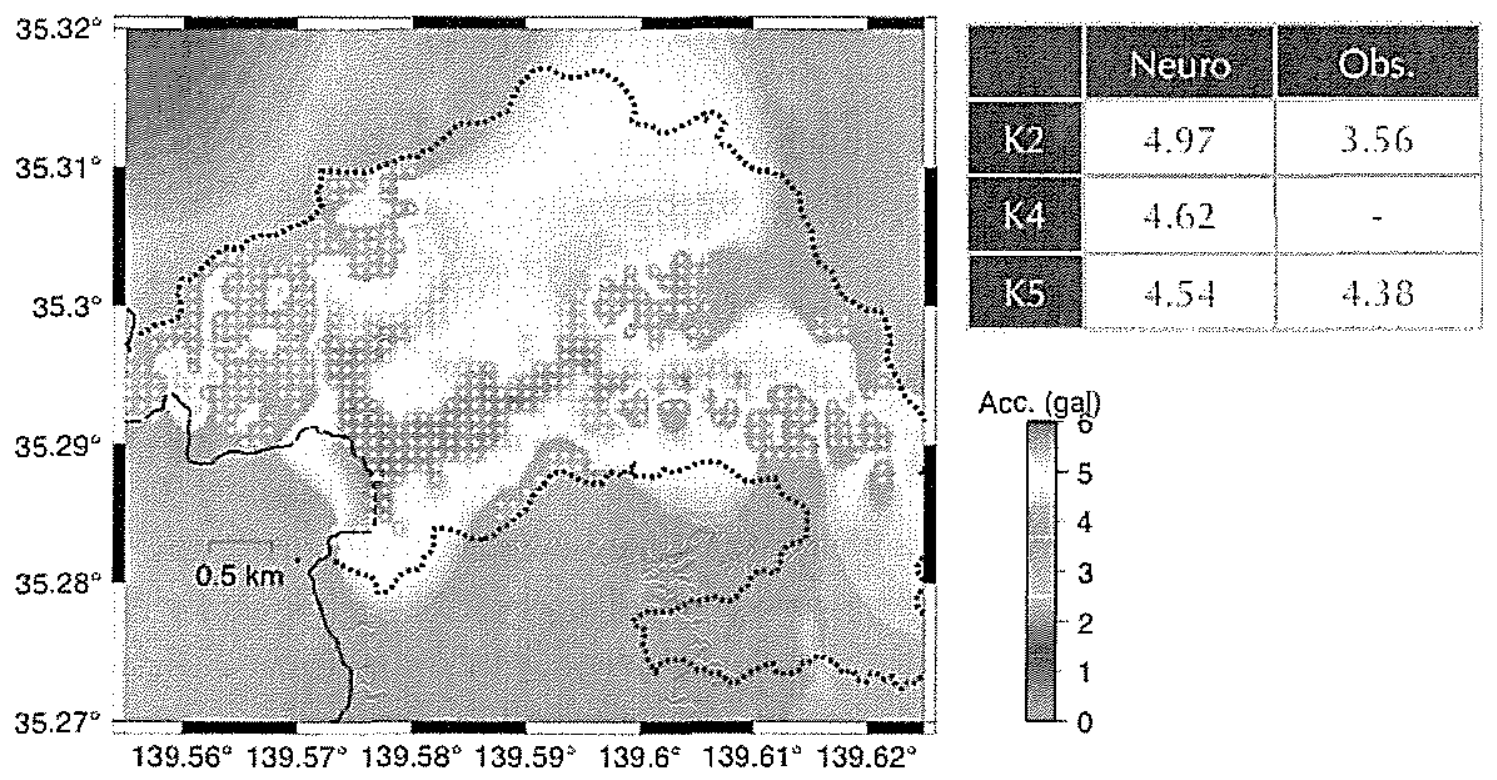

Figure 7 Estimated PGA distribution map for case 2 (Northern Chiba M4.6) 